\title{
The Vulnerability of a City - Diagnosis from a Bird's Eye View
}

\author{
Hannes Taubenböck \\ German Aerospace Center (DLR), \\ German Remote Sensing Data Center (DFD)
}

Germany

\section{Introduction}

When the tsunami in the Indian Ocean on 26 December 2004 hit the city of Banda Aceh on the island of Sumatra, Indonesia, neither the city administration nor its inhabitants, nor national or international organisations were prepared. Approximately 60.000 of the 260.000 inhabitants died, leaving other 30.000 homeless and causing an enormous impact on the local economy.

In the aftermath of this event tsunami early warning system were developed and are operated today (e. g. the German Indonesian Tsunami Early Warning System - GITEWS (Lauterjung, 2005)). However, the problem of earthquake or tsunami prediction in a deterministic sense has not been solved yet (Zschau et al, 2002). Thus, an end-to-end tsunami early warning system includes not only the tsunami warning, but also the assessment of vulnerability, perception studies, evacuation modeling, eventually leading to technical requirements for monitoring stations and recommendations for adaptation and mitigation strategies (Taubenböck et al., 2009a).

In this study we address several specific questions on the capabilities of one discipline remote sensing - for diagnosing the multi-faceted and complex vulnerability of a city:

- Which remotely sensed data sets are appropriate analyzing vulnerability in highly complex urban landscapes?

- What capabilities and limitations does urban remote sensing have regarding mapping, analysis and assessment of risks and vulnerability?

- How can interdisciplinary approaches extend the applicability of earth observation?

In general, earth observation serves as an independent and relatively cost-effective data source. Its distant view enables clarity - a principle especially true for remote sensing (Dech \& Messner, 2005). The bird's eye view provides an up-to-date and areas-wide spatial overview and at the same time capturing the small-scale heterogeneity of urban landscapes. Especially in explosively sprawling and changing urban areas of developing countries remote sensing often serves as the only reliable data source.

In recent years, airborne and spaceborne remote sensing systems and image analysis techniques have developed to an extent where civil and commercial earth observation (EO) instruments can contribute significantly in supporting the management of major technical and natural disasters as well as humanitarian crisis situations (Voigt et al., 2007). 
The use of various satellite data sets and remote sensing methods for post catastrophe damage detection was and still is topic of several studies (Eguchi, et al., 2000; Huyck et al., 2003, Saito \& Spence, 2003; Pesaresi, Gerhardinger \& Haag, 2007). As example Gusella, Huyck \& Adams (2008) used an object-oriented approach to count the number of collapsed buildings after the earthquake in Bam, Iran.

An operational service at DLR's German Remote Sensing Data Center (DFD), the "Center for Satellite Based Crisis Information" (ZKI) supports decision-makers and relief organisations. Its function is the rapid acquisition, processing and analysis of satellite data and the provision of satellite-based information products during and after natural and environmental disasters, for humanitarian relief activities, as well as in the context of civil security (www.zki.dlr.de).

In recent years, the research also focused on assessing vulnerability and risk of systems before an expected event aiming at the development of strategies of preparedness (Schneiderbauer, 2007). Earth observation data are widely used for mapping or up-dating building inventory data (Miura \& Midorikawa, 2006; Sarabandi et al, 2008) as input for multi-criteria GIS-based vulnerability studies (Rashed \& Weeks, 2003).

The work presented here is embedded in the Numerical Last Mile Tsunami Early Warning and Evacuation Information System (Last-Mile) project (Birkmann et al., 2008a; www.lastmile-evacuation.de). The city of Padang, Indonesia, has been indicated as one of the most plausible localities for a tsunami of disastrous proportions in the near future (Borrero et al., 2006; McCloskey et al., 2010). Off the coast of Padang, the Sunda Arc marks an active convergent plate boundary. Thus, the city is located in a zone of extreme high probability to severe earthquakes and potential triggered tsunamis. According to the catalogue prepared for tsunamis in the Indian Ocean, which includes about ninety tsunamis, $80 \%$ of the tsunamis are from Sunda arc region, where on an average, tsunamis are generated once in three years (Rastogi and Jaiswal, 2006). Padang is the capital city of the Sumatera Barat province in West Sumatra, and with almost one million inhabitants the third largest city on the island of Sumatra, Indonesia.

The complex and dynamic urban system of Padang features a high concentration of population, infrastructure and economic values. Padang features supra-regional relevance with an international airport, a port as well as binding to the rail network. Thus, the city possesses a central economical role for the coastal region and the mountainous backcountry. It is located directly on the coast and partially sited beneath the mean sea level.

\section{Vulnerability - a conceptual framework}

Vulnerability is a term of such broad use as to be almost useless for careful description at the present, except as a rhetorical indicator of areas of greatest concern (Timmermann, 1981). A review of the literature indicates a number of contrasting definitions of what vulnerability means, as well as numerous conflicting perspectives on what should or should not be included within the broad assessment of vulnerability in cities. Definitions and concepts on 'vulnerability' evolve from different schools and disciplines - e. g. social scienes (Bohle, 2001; Cannon et al., 2003), business sciences (Briguglio, 2003), natural sciences (Correll et al., 2001), climatology (IPCC, 2001), engineering (Correira et al, 1987) or disaster management (Blaikie et al, 1994). The various disciplines and perspectives on vulnerability show the 
multidimensionality of the concept. Holistic concepts try to incorporate its multidimensionality (Bogardi \& Birkmann 2004; Füssel, 2005; Taubenböck et al, 2008). For this paper, we adapt the definition of the UN: Subject to the considered period of time, the geographic location (system) and a scale-dependent reference system, vulnerability is the condition determined by physical, social, economic and environmental factors or processes, which increase the susceptibility of a community to the impact of hazards (UN/ISDR, 2004). Vulnerability is also part within the higher-ranking risk concept. The UN (2004) determined that the risk to a particular system has two factors. One factor is the "hazard" itself, which is a potentially damaging physical event, phenomenon, or human activity that is characterized by its location, intensity, frequency, and probability. The second factor is "vulnerability," which denotes the relationship between the severity of hazard and the degree of damage caused. Thus, risk results from a future interplay of a hazard and the various components defining vulnerability. The effect of a natural hazard on the objects or people of a particular area exemplify the complex interrelationships and emerging domino effects.

However, we are still dealing with a paradox: we aim to measure vulnerability, yet we cannot define it precisely (Birkmann, 2006). The various approaches, concepts and definitions are on an abstract level and objectively quantification or measurement thus is a complex task. Indicator systems are usually used to resolve the abstract term 'vulnerability' into measurable parameter (Bollin \& Hidajat, 2006).

Components specifying vulnerability include the physical, demographic, social, economic, ecological and political aspects contributing and adding up to the holistic conceptual idea (Table 1). This conceptual idea adapted for this study uses a meta-framework applicable to various systems (e.g., urban areas), various elements or attributes within a system (buildings, people, environmental services, etc.), various scales (local, regional, national, global), and various hazards (earthquake, tsunami, landslides, climate change, etc.). In general the various components described above suggest the complexity of dynamic interactions and interdependencies evolving in a system in case of a disastrous event. This highlights the need for multidisciplinary scientific approaches to converge on the problem of holistic identification of vulnerability (Taubenböck et al., 2008).

To converge on the problem of assessing the complexity of risk and vulnerability, the rather abstract components of this meta-framework need further partitioning. Specifications are dependent on the considered system and the type of hazard. In our case, indicators are developed for the example of an "urban system prone to a tsunami hazard". A consistent systematization itemizes the components into a set of measurable indicators contributing to all the various stages of the risk management cycle. As example, higher-ranking physical vulnerability is hard to determine, but one of many indicators such as number of affected buildings, enables quantification of the situation. An indicator is defined as a variable, which is a representation of an attribute, such as quality and/or characteristics of a system (Gallopin, 1997). The quality of the indicator is determined by its ability to indicate the characteristics of a system which are relevant to the underlying interest determined by the goal or guiding vision (Birkmann, 2006b). The result is an arbitrary number of measurable indicators contributing aspects to the associated component and to the ranking in the holistic conceptual framework (Table 1).

The overall conceptual framework serves as the basic outline to identify capabilities and limitations of remote sensing data and methods to contribute to the holistic concept. 


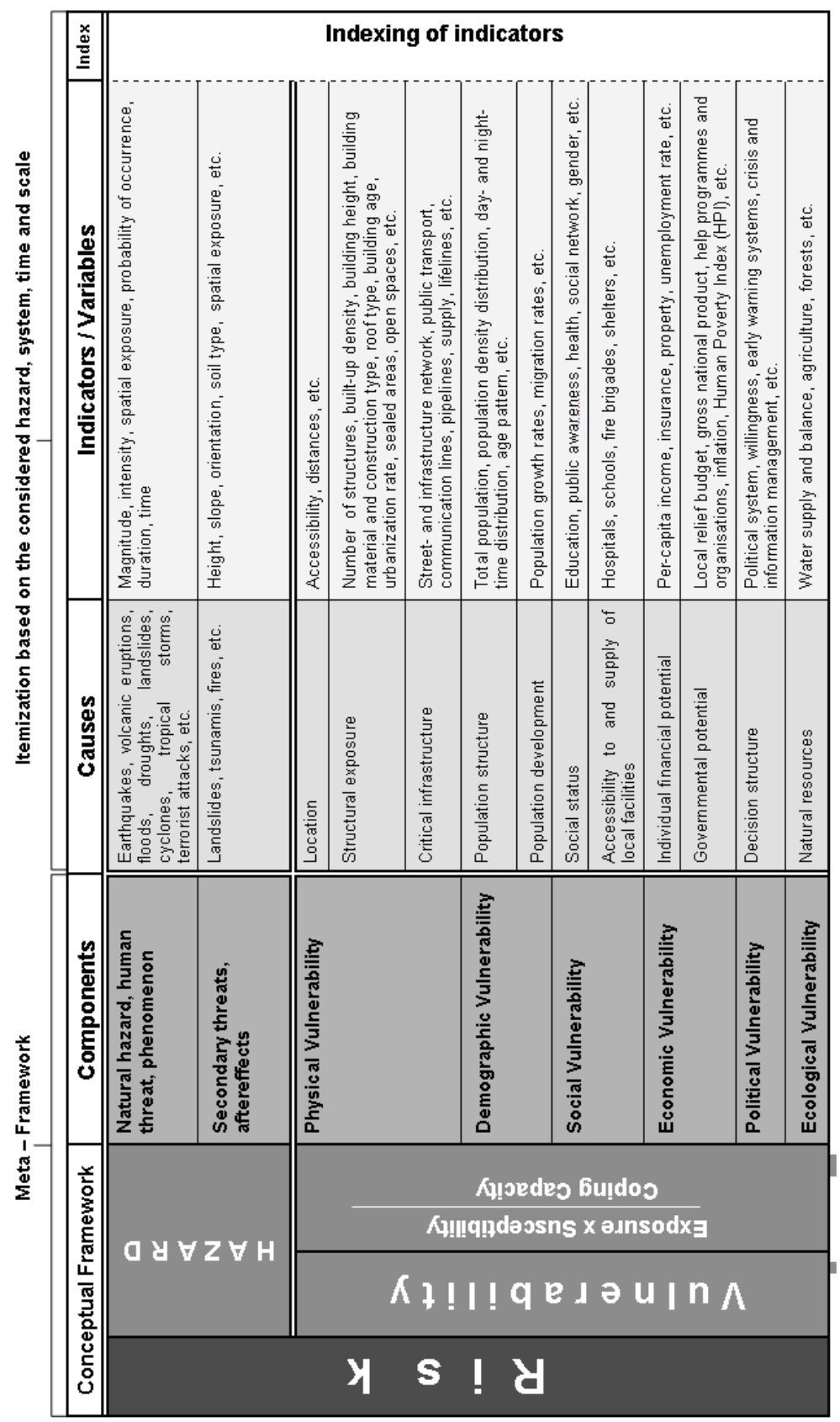

Table 1. A hierarchical holistic framework conceptualizing hazards, vulnerability and risk to derive a selection of measurable indicators for a specified system (adapted from Taubenböck et al., 2008) 


\section{Diagnosis of a city's vulnerability to tsunami hazards using earth observation}

\subsection{Remotely sensed data sets}

With respect to the holistic idea of vulnerability and risk concepts the question arises why remotely sensed data sets should be used addressing this topic? In general, because remote sensing provides spatially consistent data sets that cover large areas with both high spatial resolution and high temporal frequency. In particular in developing countries where geoinformation is rarely available earth observation is often the only up-to-date, area-wide and independent data source and thus indispensable.

However, the capabilities of various sensors reach far beyond the obvious benefits available at popular platforms like Google Earth or Bing. They provide reflective responses all along the electromagnetic spectrum which enables detection of objects or patterns of the earth's surface and their condition. Remote sensing platforms and sensors cover many spatiotemporal dimensions, with a flexible repetition rate and in various scales ranging from spatially detailed analysis on single buildings or building block level to global studies on continental scales for various urban applications (Taubenböck \& Dech, 2010):

Very high resolution multispectral optical satellite data from i. e. GeoEye I, WorldView I \& II, Ikonos (cp. Fig. 3), Quickbird, CARTOSAT, SPOT or RapidEye feature a geometric resolution ranging from $41 \mathrm{~cm}$ to $5 \mathrm{~m}$, which is feasible for the small-scale objects typical in urban environments. A highly detailed spectral coverage of the electromagnetic spectrum by hyperspectral sensors like the airborne sensors HyMap, AVIRIS (or in the near future the German satellite EnMAP) enable derivation of surface materials or land surface temperature in high geometric resolution from $2 \mathrm{~m}-30 \mathrm{~m}$. Laser Altimeter (LIDAR) is also an optical remote sensing technology for highly detailed profiles of 3D elevations of the earth's surface; stereo images can also be used for that purpose. In terms of temporal analysis, optical sensors such as Landsat (since 1972), SPOT (1986), or IRS (1988) enable monitoring and detection of changes with reduced spatial resolution.

In addition to optical systems, SAR antennas operate almost independently of meteorological conditions and solar illumination. Thus, they are especially in often cloudy areas of high importance. There are, at present several SAR sensors in space as well as data from past missions offering a broad and global observation of the planet (e.g., ERS-2, RadarSat, Envisat, TerraSAR- $X$, and the space shuttle) in different frequencies, polarizations, and geometric resolutions. In addition, interferometric digital elevation model (DEM) can be derived, such as the X- and C-band data from the Shuttle Radar Topography Mission (SRTM) are used to analyze the terrain situation. It is a surface model with a pixel-spacing of 25 meters, and thus enables a rather coarse overview. Future missions, like TanDEM-X will provide a higher geometric detail of up to 12 meters. Even aerial acquisitions are possible due to the full-time imaging potential of radar. Furthermore, new radar satellites such as TerraSAR-X, CosmoSkyMed, and Advanced Land Observing Satellite (ALOS) enable the extraction and analysis of urban structures based on geometric resolutions up to $1 \mathrm{~m}$ (Roth et al, 2005).

Satellites from EUMETSAT enable to monitor current weather situations to include predictions of heavy rainfall or cyclones, etc.; however, this field of application is not part of our study.

\subsection{Mapping}

The data and images presented and described above are data not information. The strength of remote sensing with its synoptic overview allows independent, fast, up-to-date, area-wide 
and relatively cost-effective transformation of data (or images) into information (Taubenböck \& Dech, 2010). Making use of a vast amount of methodologies - e.g. statistical-, neural-, fuzzy classifiers - for automatic information extraction for particular data sets (Mather, 2004) this transformation leads to application-driven products. As example, we used an object-oriented, multi-level, hierarchical classification approach (Taubenböck et al, 2010) to derive the land-cover of Padang from Landsat as well as Ikonos data in combination with a digital surface model (DSM). Beyond the spectral information within the remotely sensed data, the fuzzy logic-based object-oriented approach allows to use shape, neighbourhood, hierarchical and context information (cp. Fig. 1).

A pixel-based classification approach extracting urban and non-urban structures from a single TerraSAR-X image has also been applied (Esch et al., 2010). The urban footprint is extracted by analysing the speckle characteristics of a TerraSAR-X scene based on an estimation of the local coefficient of variation and the fading texture of the whole scene. The basic concept is to extract reliable urban features as seed points, which are represented by bright point scatterers (corner reflectors) for the urban footprint classification. The 'urban seeds' depict especially the reflection information of vertical structures. Urban seeds are extracted from intensity and texture, derived from a two-tiered speckle divergence calculation with a $9 \times 9$ and a $35 \times 35$ window. To derive the urban footprint, analysis techniques are used to densify and generalize the detected urban seeds (Esch et al., 2010).

For multi-temporal urban growth analysis the urban footprint classifications from Landsat of the years 1989 and 2000 and from TerraSAR-X of 2010 were combined. Post-classification comparison was found to be the most accurate procedure and had the advantage of indicating the nature of the changes (Mas, 1999).

Fig. 1 shows various results: Multi-temporal urban change detection of a multi-sensoral approach using Landsat and TerraSAR-X data of the coastal urban area of Padang (Fig 1a). The result allows detecting, quantifying and localizing spatial urbanization over time on urban footprint level. The result displays extensive urban sprawl as well as re-densification in the urban center in Padang over the last two decades. The geo-spatial product allows a first assessment of areas of high vulnerability due to natural hazards.

For mapping the complexity of the urban environment, multi-sensoral data processing of high resolution optical satellite data in combination with a high resolution airborne digital surface model allows the derivation of a 3D city model (Fig. 1d). The results are eight classes mapping the urban morphology-houses, streets, sealed areas, grassland, trees, wetland, bare soil, and water. This is e.g. relevant for identification and quantification of the building stock, built-up density, floor-space index, building heights, vegetation fraction, infrastructure, or undeveloped areas (Fig 1 b \& c). In terms of vulnerability an inventory of the urban morphology is an essential information basis for urban planning and risk reduction strategies.

\subsection{Analysis}

Beyond the capabilities of mapping the city remotely sensed data sets and results can be used for analyzing the urban structure as well as the natural conditions in and around the urban landscape in the context of hazards and vulnerability.

Regarding hazards, e. g. the inclination of the slope is computed using a digital elevation model (SRTM) with a tangent equation taking neighbouring pixel height values into account. The result projects the spatial distribution of the steepness of slopes, which serve as 

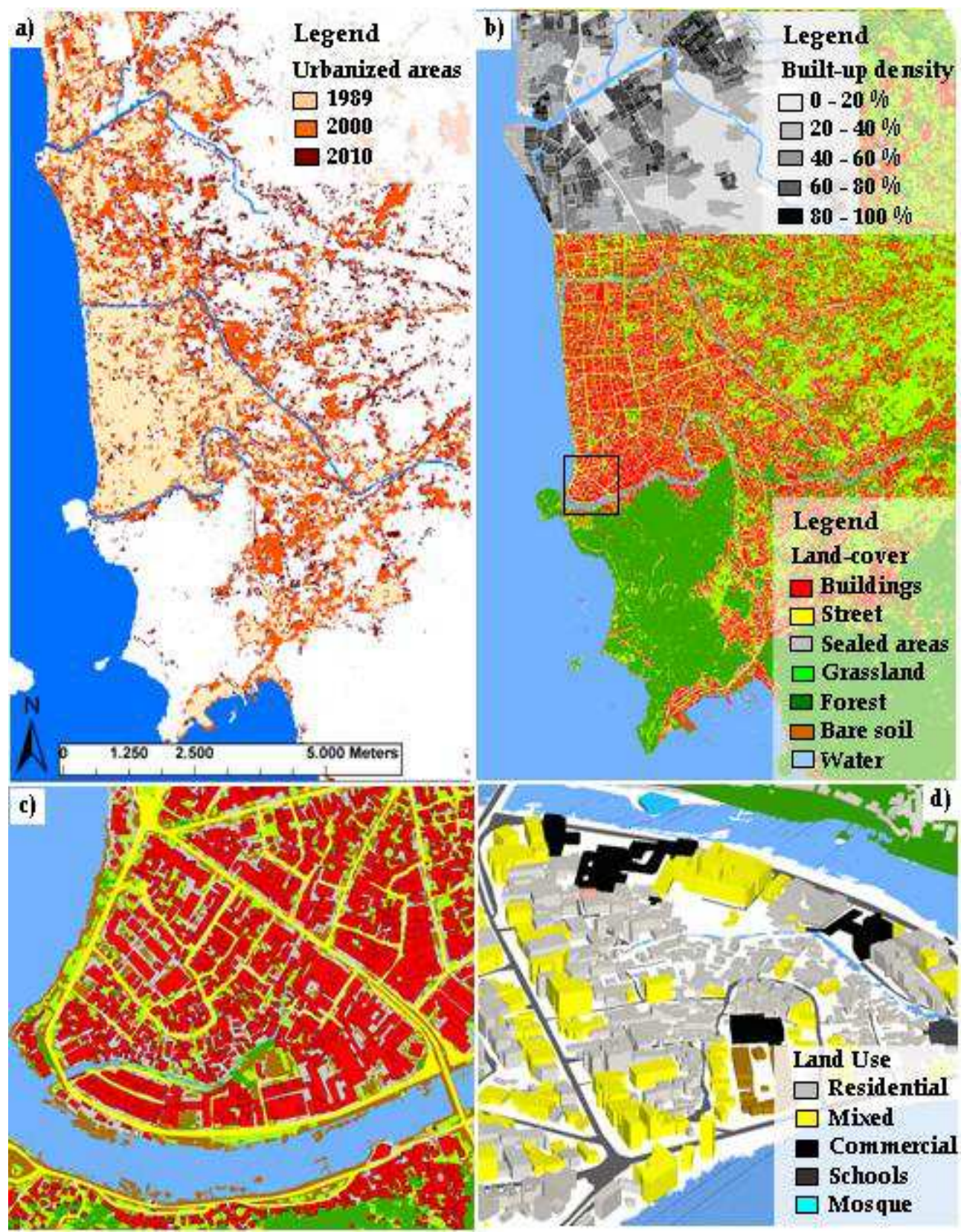

Fig. 1. Classification of multi-sensoral remotely sensed data a) Change detection from 1989 until 2010 on urban footprint level b) Land cover classification on high geometric resolution and built-up density derivation on block level c) Detail of the land-cover classification d) 3$\mathrm{D}$ city model and integration of land use 
one component to identify areas at categorical risk for landslides as secondary threat of an earthquake. Of course, steepness is not solely decisive for the occurrence of landslides, but it does provide a spatial containment to possible areas. Figure 2a displays critical slopes with an inclination of 10 degrease and higher along the coastal area of Padang.

The height information in combination with the orientation of the slopes calculated from the DEM is also used to approximately assess affected areas in case a tsunami wave hits the urban coastline. The calculation is based on the coastline extracted from a land cover classification from Ikonos data (cp. Fig 1b). The DEM allows a coarse identification of areas prone to a potential tsunami wave. Figure 2a indicates areas lower than 4 meter above sea level and thus of highest spatial exposure.

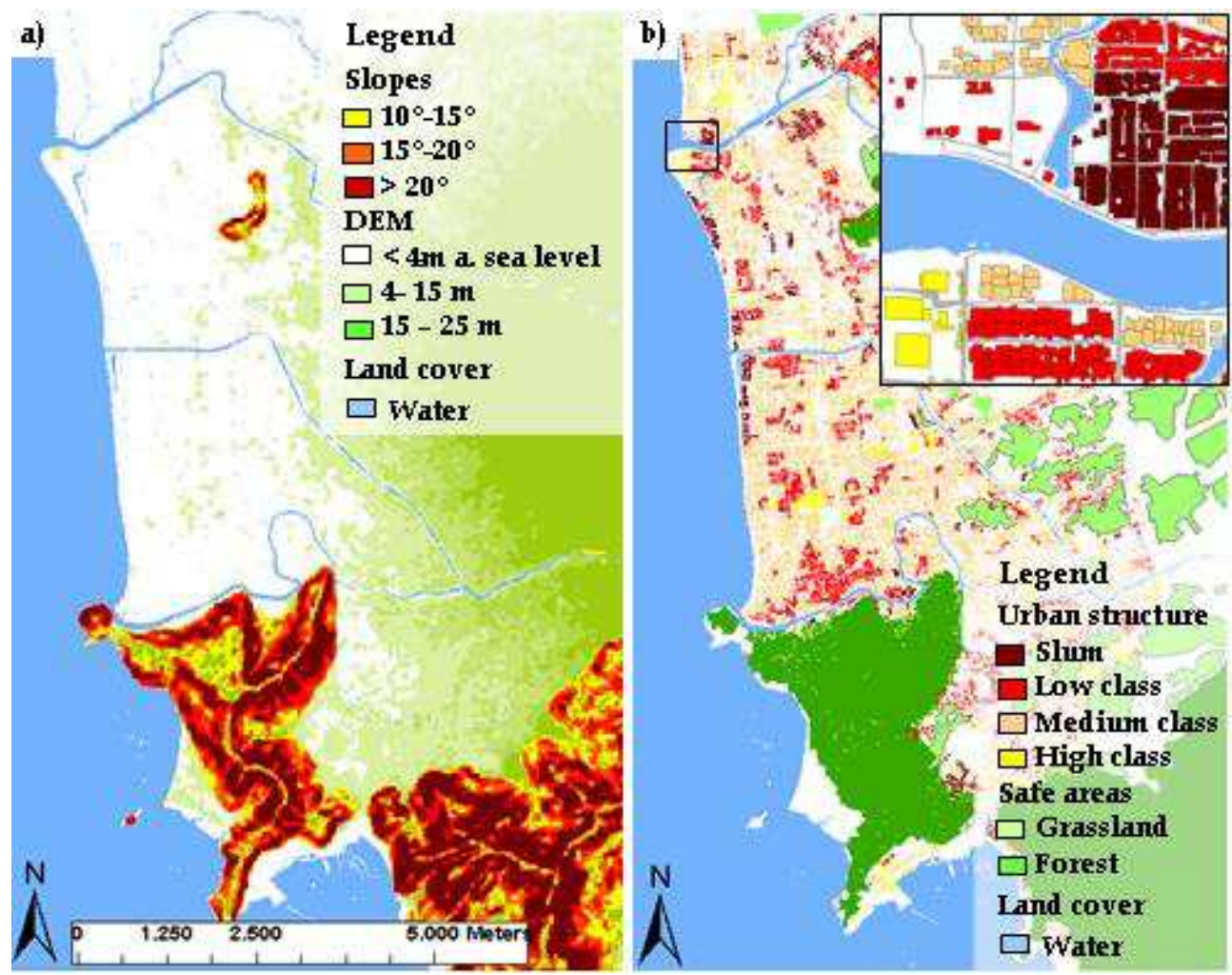

Fig. 2. Physical parameters - Structural types

Risk and vulnerability is an inherently spatial problem. Cities contain physically different urban structures. Subdividing the complex urban landscape into homogeneous units aims at deriving meaningful entities for vulnerability assessment. Therefore the land-cover classification (cp. Fig. 1b) and the physical parameters, such as built-up density, location, alignment or heights, are used for a semantic classification of urban structure types. As example, the building density is displayed in figure $1 \mathrm{~b}$ for a part of the city of Padang. The idea of semantic classification aims at a first assumed evaluation of vulnerability between physically homogeneous sectors within the city's landscape. 
The approach for semantic classification is generic, aiming at transferability on any urban area throughout the world with similar physical parameters available. Therefore, we used descriptive statistic values as Quartile (Q1, Q3), Median (Med) or Mean (M) to subdivide the different classes. The six resulting semantic classes are defined by the following statistical borders. An example, we classify 'informal settlements' using built-up density values higher than the third quartile (Q3) of the complete spectrum of the built-up density values classified in Padang. Analogous, the buildings of informal settlements are assumed to be smaller than Q3 and lower than Q1 of the particular spectrum of values classified for the city of Padang. Utilizing these statistical parameters the classification is not affected by cultural or regional characteristics of urban morphology occurring worldwide. With respect to this methodology, only the semantic nomenclature has to be adjusted on the particular structures and locations.

Figure $2 \mathrm{~b}$ displays six different urban structure types- 'informal settlements (slums)', 'suburbs', 'low class areas' (LC), 'middle class areas' (MC) and 'high class areas' (HC). As an example, slum areas are defined by the highest built-up density measured within the urban environment with mostly one storey buildings, with the smallest buildings sizes. With the nomenclature 'slum' the classification by solely physical parameters sets a first hint at building quality and thus, stability and also in the direction of assumed socioeconomic relevance.

\subsection{Assessment}

The city, seen as a human product, is the physical and architectonic reflection of the society that created it (Gonzalez \& Medina, 2004). Thus, the data and products indirectly contain additional information. The products presented above refer to land cover, which is defined as the physical material on the surface, while land use refers to the human activity that takes place on, or makes use of that land. The fundamental problem for remote sensing is that while there is often a relatively simple and direct relationship between land cover type and detected spectral reflectance, the same is seldom true for land use. Nevertheless, physical parameters like building sizes and heights, roof types, etc. often indirectly correlate to the usage of the buildings.

As figure 3 visualizes the buildings classified as industry or university clearly differ in alignment, size and shape from buildings classified as residential areas. Thus, the physical parameters of the urban morphology can be used for systematic detection of probable nonresidential areas. The type of usage, like in this case industry or university needs to be integrated from external knowledge, like e. g. field surveys or data bases from the city.

Furthermore it is obvious, that the knowledge on this physical and semantic information on urban morphology (building size, height, occupancy, location, semantic class) allows indirect conclusions about the population distribution, even on its spatiotemporal shift within the course of a day.

On the basis of the punctual information of population data (1000 households) collected through fieldwork (UNU-EHS, 2008) the mathematical concept is based on a bottom-up extrapolation. For the different semantic classes the particular punctual information is averaged to get a characteristic number of inhabitants per $\mathrm{m}^{2}$ per semantic class. The results for the residential areas are listed in table 2. In addition, the survey included other occupancies, like industry, offices or markets. These results are displayed in table 3 . With these external data sets the extrapolation is calculated with respect to semantic classes and the knowledge of living spaces per individual house in the particular areas. 

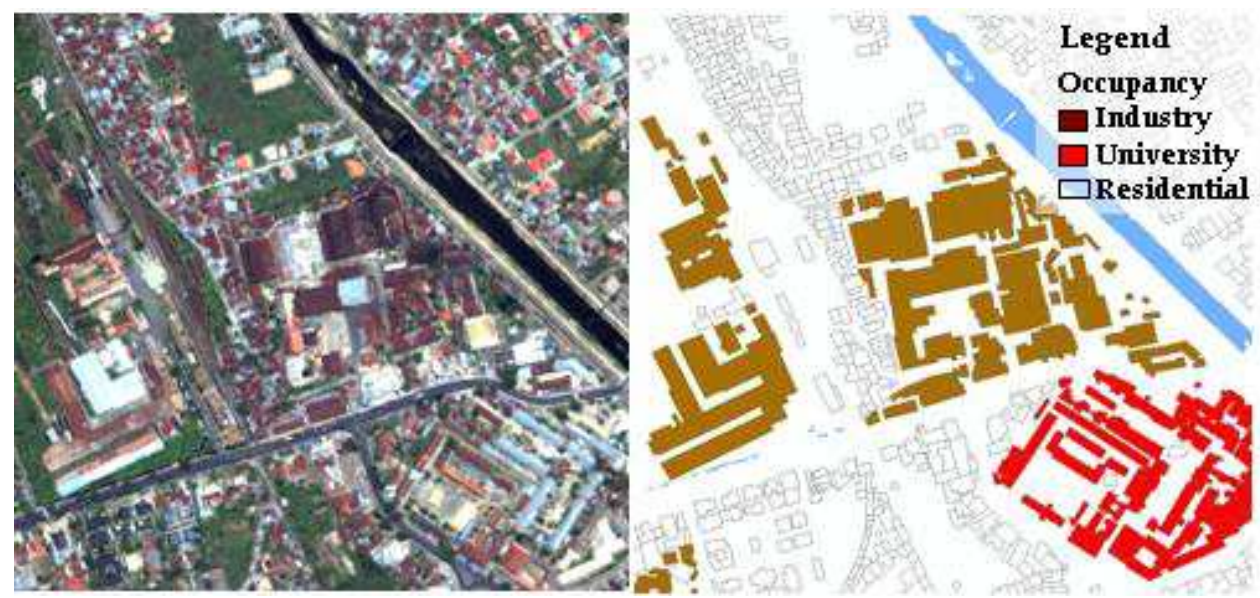

Fig. 3. Structural differences between various occupancies of buildings visualized in Ikonos imagery and in the classification result

\begin{tabular}{|l||c|c|}
\hline \multicolumn{1}{|l||}{ Semantic Classes } & \multicolumn{2}{c|}{ Living space per inhabitant (Li) } \\
\hline & day & night \\
\hline class 1: "SLUM" & $49.2 \mathrm{~m}^{2} / \mathrm{p}$ & $26.1 \mathrm{~m}^{2} / \mathrm{p}$ \\
\hline class 2: "LC" & $93.3 \mathrm{~m}^{2} / \mathrm{p}$ & $47.5 \mathrm{~m}^{2} / \mathrm{p}$ \\
\hline class 3: "MC" & $133 \mathrm{~m}^{2} / \mathrm{p}$ & $54.5 \mathrm{~m}^{2} / \mathrm{p}$ \\
\hline class 4: "SUBURB" & $48.2 \mathrm{~m}^{2} / \mathrm{p}$ & $31.5 \mathrm{~m}^{2} / \mathrm{p}$ \\
\hline class 5: "HC" & - & - \\
\hline class 6: "residuals" & $58 \mathrm{~m}^{2} / \mathrm{p}$ & $41 \mathrm{~m}^{2} / \mathrm{p}$ \\
\hline Without semantic classes & $93.3 \mathrm{~m}^{2} / \mathrm{p}$ & $47.0 \mathrm{~m}^{2} / \mathrm{p}$ \\
\hline
\end{tabular}

Table 2. Mean living space for various semantic classes of residential areas

Figure 4 shows a bottom-up distribution of punctual population data for the entire city of Padang. Figure 4a displays population at the morning per building - e. g. localizing high population density in market areas, schools, etc.. Figure $4 \mathrm{~b}$ shows the population flux between day- and night-time and reveals a spatial shift of vulnerability, e. g. the highly prone market areas at day-time are almost empty and thus less vulnerable at night-time. Beyond the indirect assessment of time-dependent population assessment the semantic classification already hints at socio-economic parameters of the people residing in these areas. As an example, densely populated areas generally correlate to high poverty and low quality housing, economic and social components of vulnerability.

A study proved that also a correlation between physical urban morphology and socioeconomic parameters of the people is basically given (Taubenböck et al., 2009b). The sample parameters "income per month" and "value of property" were related to the various semantic classes. The results confirm the hypothesis that the physically classified "informal settlements" and "suburbs" represent lowest income and property values. With slight variations - a linear correlation can not be detected in such a complex environment - a 
consistent rising of income levels is revealed to "low, middle and high class" areas. Thus, remote sensing may provide a cost-effective method to reduce, but not replace extensive ground data collection and provide spatial value-adding via interdisciplinary cooperation.

\begin{tabular}{|l||c|c|}
\hline \multicolumn{1}{|l||}{ Semantic Classes } & \multicolumn{2}{c|}{ Working spaces per inhabitant (Li) } \\
\hline & day & night \\
\hline office, bank, and other commercial usage & $20 \mathrm{~m}^{2} / \mathrm{p}$ & $1000 \mathrm{~m}^{2} / \mathrm{p}$ \\
\hline shopping mall, market & $10 \mathrm{~m}^{2} / \mathrm{p}$ & $100 \mathrm{~m}^{2} / \mathrm{p}$ \\
\hline industrial facilities & $10 \mathrm{~m}^{2} / \mathrm{p}$ & $30 \mathrm{~m}^{2} / \mathrm{p}$ \\
\hline harbour, railway station, sports facility & $20 \mathrm{~m}^{2} / \mathrm{p}$ & $100 \mathrm{~m}^{2} / \mathrm{p}$ \\
\hline mosque & - & $1000 \mathrm{~m}^{2} / \mathrm{p}$ \\
\hline school, university & $10 \mathrm{~m}^{2} / \mathrm{p}$ & $1000 \mathrm{~m}^{2} / \mathrm{p}$ \\
\hline
\end{tabular}

Table 3. Mean space for various semantic classes of commercially used areas

Besides interdisciplinary contributing to the demographic, social or economic sphere of the vulnerability framework, physical stability analysis of the structures is an essential step to identify physical vulnerability. In fast changing, complex and small-scale urban environments the identification and localization of vulnerable as well as stable structures is therefore the basic element to implement mitigation strategies and to reduce vulnerability. With almost 100.000 buildings within the study area (cp. Figure 1 \& 2) surveying of the complete building stock is out of reach for time and cost reasons.

An interdisciplinary analysis of civil engineering and remote sensing aims at overcoming this problem: On the one hand civil engineering allows a highly detailed stability analysis of individual buildings by an extensive house by house inspection. For Padang, 500 buildings have been surveyed gathering data on their physical characteristics like e. g. height, material, existence of columns, foundation of main structures, existence of stirrup or/and main beam or damage due to previous earthquakes. In combination with physical tests, like the hammer test on supporting pillars, the stability of the structures was assessed individually. An additive approach was applied for the various physical parameters and a normalized vulnerability (stability) index calculated $(100=$ stable structure; 0 instable structure). The sample selection of the surveyed buildings aimed at a complete coverage of differing housing types -from small, low height shacks to large, high-rise building types, equally distributed within the entire city area of Padang. 500 buildings out of almost 100.000 are comparably few. The challenge consists of a value-adding combination of civil engineering and remote sensing.

The capabilities of remote sensing are area-wide, up-to-date, and quantitative derivation of physical characteristics of the complete building stock. On the other hand the capabilities of remote sensing allow area-wide, up-to-date, and quantitative derivation of physical characteristics of the complete building stock, with comparatively to in-situ surveys limited knowledge on structural parameters. Structural parameters from remote sensing are limited to roof colour and type, height and size. The high variability of roof colours does not enable any correlation to the stability of the structures. Thus, we plotted the stability of the surveyed buildings to their size combined with height (volume of the structure) against each other (Fig. 5). 


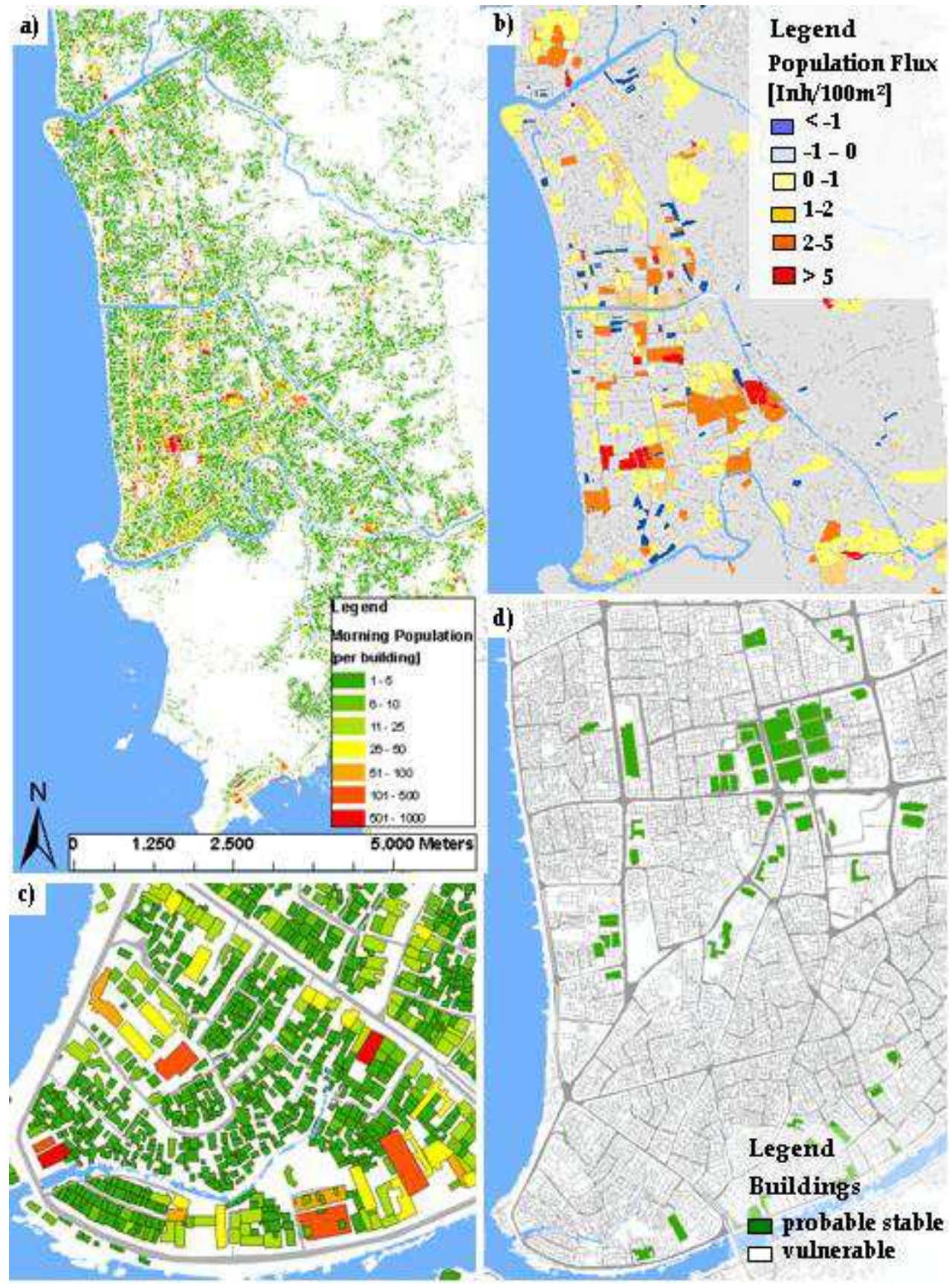

Fig. 4. Population distribution in dependence of daytime, population flux and assessment of buildings suitable for vertical evacuation 


$$
\begin{aligned}
y=0,0021 x^{4}-0,4119 x^{3} & +28,419 x^{2}-779,16 x+6922,1 \\
R^{2} & =0,4068
\end{aligned}
$$

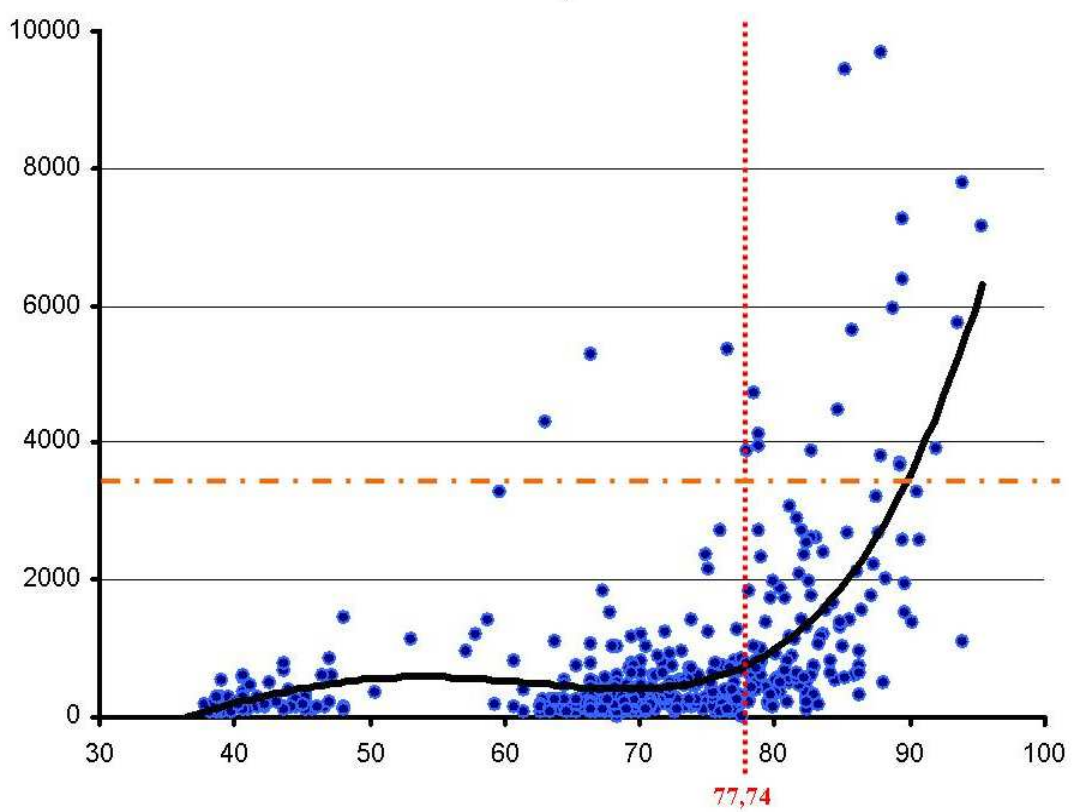

Fig. 5. Correlation of building volumes derived from remote sensing with the vulnerability analysis of the particular buildings from a civil engineering survey

The result does not show an obvious correlation, but reveals that buildings with a higher stability (vulnerability value) predominantly show a higher building volume. In our case we identified an $85.71 \%$ probability for a stable structure for buildings with a volume higher than $3500 \mathrm{~m}^{3}$. The extrapolation on the complete building stock using the 3-D city model identified 183 buildings with a high probability to be appropriate for vertical evacuation. The interdisciplinary analysis thus allows reducing the amount of buildings to be surveyed for a final official designation as vertical evacuation shelter from 100.000 to 183 , which is feasible for surveys.

\subsection{Accuracy assessment}

The synoptic overview of remote sensing products in the previous chapters show area-wide and spatially highly detailed information extraction, but the accuracy of cadastral data sets is not achieved.

On urban footprint level, the large amount of mixed spectral information in such a coarse ground resolution - caused by multiple land covers within the lowest granularity of one pixel - the accuracy is limited. But for the requirement of mapping the large city footprint, its spatial dimension and the spatial developments over the years, the Landsat and TerrSAR-X images provide enough information for an assessment of urban change (cp. Fig 1). The accuracy of every classification result was assessed with 250 randomly distributed pixels. Due to missing ground truth data at historic times, the accuracy was assessed visually by comparing classification results to the Landsat data. Thus, this assessment of 
accuracies already includes uncertainties. Even so, the high overall accuracies range from $86 \%$ to $93 \%$ correctly classified pixels. For TerraSAR-X data a comparison with the high resolution settlement mask revealed an accuracy of the urban footprint classification in 2010 of $79.2 \%$ (Taubenböck et al, 2011).

On highest resolution the implemented automatic object-oriented, hierarchical classification methodology showed an accuracy of $84.2 \%$ correctly detected houses. Manual revision enabled to raise the accuracy to $97 \%$. The remaining land cover classes of bare soil, grassland, forest, sealed areas, streets, water range between $80 \%$ and $95 \%$ accuracy. Consequently, the inferred products of the land cover classification for analysis of the urban landscape or the surface (e. g. building density, vegetation fraction, etc.) inherit the errors from the classification results. The accuracy of the land use classification has been tested with field observations. As the algorithm applies residential usage by default and changes the occupancy only if the described structural components apply, accuracy assessment has been carried out for non-residential buildings. The result reveals that the indirect derivation of non-residential occupancies is with $92.4 \%$ correctly identified structured highly accurate. But, remote sensing shows clearly limitations regarding the amount of not detected nonresidential areas, due to e. g. business, office or working activities in buildings structurally similar to residential neighbourhoods. Thus, the producer's accuracy is with $47.4 \%$ comparatively low.

The accuracy for the indirect assessment of population distribution, the population flux or the building stability from remotely sensed products has been assessed as well. For the population distribution, accuracy assessment was performed by means of 500 remaining buildings from a field survey not used for the calibration of the extrapolation algorithm. The assessment shows the compliance of field work results from the questionnaire with the calculated population per house based on the extrapolation algorithm. Table 5 presents a comparison between extrapolation results: In one section is the accuracy achieved by extrapolation using spatial specification by semantic classes as listed. This shows the accuracy of the remaining field survey data for a specific semantic class with the extrapolated data. In the other section, the extrapolation based on the mean value of living space per person for all surveyed residentially used buildings is presented as comparison.

The extrapolation using spatial structuring of the complex urban environment results in significant higher accuracies than averaging the entire city.

\begin{tabular}{|l|c|c|c|c|}
\hline Classes & Semantic classes & STD & Mean value & STD \\
\hline class 1 - SLUM & $94.21 \%$ & 1.91 & $63.08 \%$ & 2.43 \\
\hline class 2 - LMC & $89.48 \%$ & 3.32 & $73.11 \%$ & 3.95 \\
\hline class 3 - MC & $83.82 \%$ & 6.79 & $80.03 \%$ & 6.13 \\
\hline class 4 - SUBURB & $87.56 \%$ & 7.82 & $79.56 \%$ & 9.12 \\
\hline class 5 - HMC & - & - & - & - \\
\hline class 6 - residuals & $74.27 \%$ & 9.41 & $68.09 \%$ & 10.24 \\
\hline Complete (AOI) & $86.73 \%$ & 5.71 & - & - \\
\hline \hline $\begin{array}{l}\text { Without spatial } \\
\text { differentiation (AOI) }\end{array}$ & - & - & $72.12 \%$ & 9.34 \\
\hline
\end{tabular}

Table 5. Accuracy assessment of the extrapolation algorithm and comparison of the approach utilizing semantic classes and the approach utilizing a mean value 
For the building stability assessment a probability of $85.71 \%$ has been calculated that the extrapolation applies to stable shelters for vertical evacuation. However, this accuracy assessment should not lead to a definite designation of the identified potential buildings as vertical shelters, but as a containment of possibilities.

\section{The earthquake in Padang on the $30^{\text {th }}$ September 2009}

On September 30, 2009, a severe earthquake took place in the Indian Ocean with a magnitude of 7.6 and several aftershocks. The epicentre was registered about $50 \mathrm{~km}$ northeastern of Padang in a depth of $85 \mathrm{~km}$. Heavy shocks caused the collapse of many buildings and bridges, fires broke out and major parts of the technical infrastructure failed. More than 770 people died, more than 2100 are injured (information of October 2, 2009). A second earthquake with a magnitude of 6.6 occurred hours later on October 1 near the town of Sungai Penuh. In the capital city of Padang, 383 people were killed, public services such as electricity and water were disrupted, and major markets and transport routes were destroyed or badly damaged (Mercy Corps, 2010).

Here as well, hundreds of houses were damaged, two people died and a large number became injured or homeless. Strong rain make rescue work difficult and caused landslides in some areas of the affected region. The International Charter on Space and Major Disasters was triggered to provide post-disaster satellite imagery for damage mapping and to support the aid response (www.zki.dlr.de).

The rapid mapping activities of ZKI of the DLR were substantially supported with the manifold available data sets from the pre-disaster phase. While usually damages are mapped using post-disaster data on a raster basis of 250 meters, the preparation within the Last-Mile consortium enabled to now deliver fast and reliable information on individual building level. The combination of the 3-D city model, the population distribution, the street network, the knowledge on safe areas, etc. with post-disaster remote sensing data, allowed within a few hours and days to provide a fast and more detailed spatial and quantitative information for rescue teams than ever before in the history of remote sensing. Figure 6 shows an overview on partly or completely damaged structures after the earthquake on $30^{\text {th }}$ of September 2009 using post-disaster satellite data. Additionally the location of critical infrastructures such as hospitals or schools is displayed.

\section{Interdisciplinary outreach within the conceptual framework}

The holistic idea of the risk and vulnerability framework (cp. Table 1) reveals that earth observation data and methods are especially appropriate analyzing spatial exposure due to natural hazards as well as physical vulnerability indicators. In the assessment part indirect correlations with external data sets from social sciences or civil engineering revealed the capability of interdisciplinary approaches to overcome the limitations of one single discipline.

The combination of geo-spatial information products from remote sensing in combination with data, methods and results of inundation modelling allows high precision risk identification, localization and evaluation (Goseberg \& Schlurmann, 2009). The combination of the physical urban morphology with socio-economic parameters allows statements on socioeconomic patterns, and thus susceptible areas (Setiadi et al., 2010). The time-dependent knowledge on population distribution is a vulnerability indicator itself, but can additionally serve in combination with the knowledge on the street network and the width of streets, etc. to 


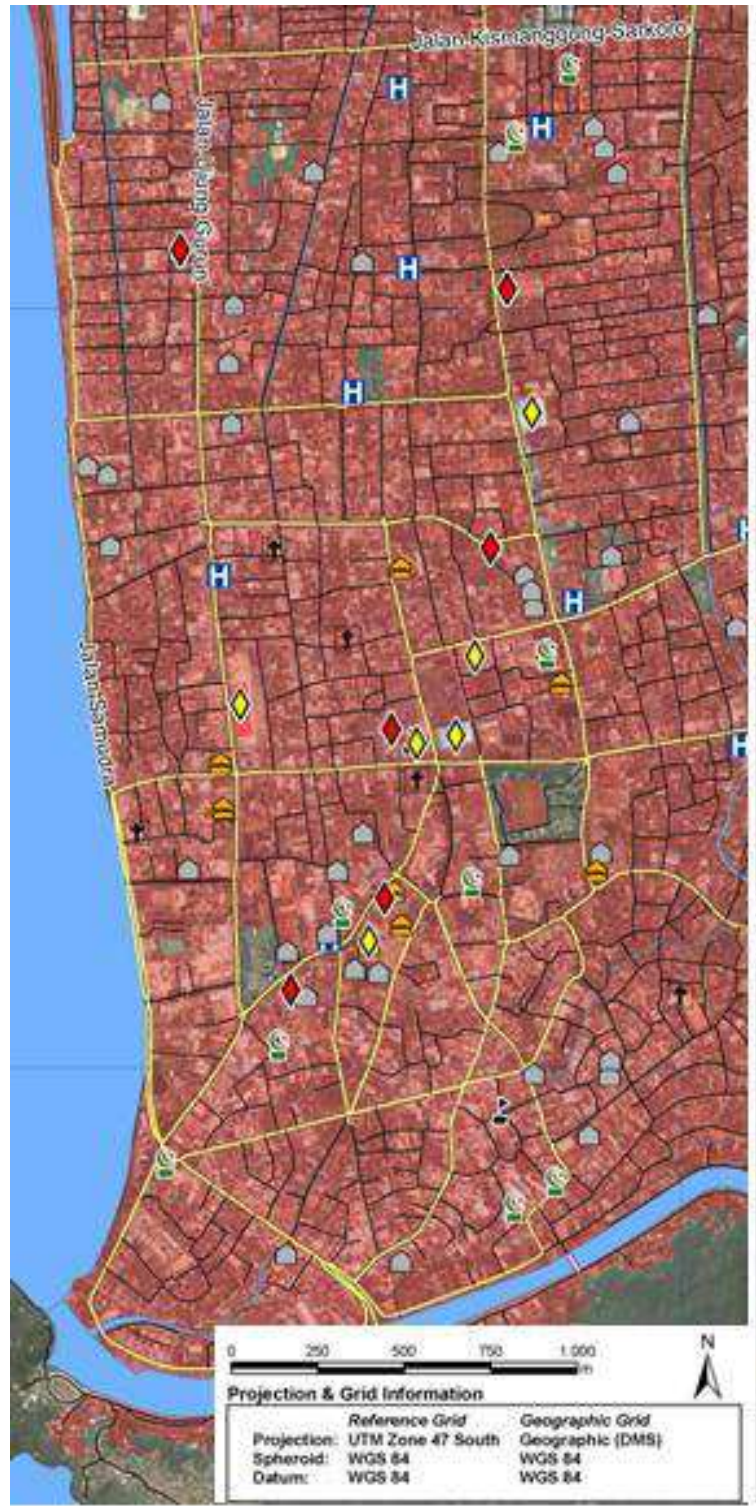

Charter Call ID 274, Product $n^{*} 02$ GLIDE number: TS-2009-000211-IDN

\section{INDONESIA - Padang Earthquake - Situation Map Padang South Scale: $1: 15,000$}

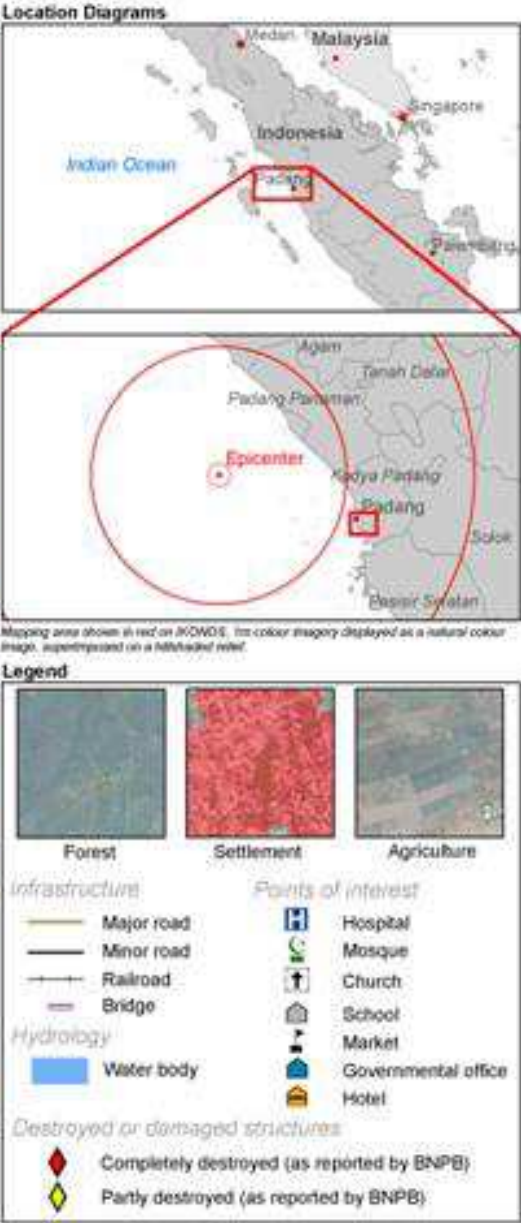

Fig. 6. Rapid mapping post-disaster analysis using pre- and post disaster satellite data and geo-spatial products (www.zki.dlr.de)

model evacuation scenarios (Borrero et al., 2006; Lämmel, Grether \& Nagel, 2010). The combination of area-wide and up-to-date available physical parameters of the building stock derived from remote sensing in combination with civil engineering (Leone et al. 2007; Münich et al., 2006) can also support the latter approach with the actual distribution of vertical shelters. 
The multidimensional information on physical, demographic, social or economic parameters in combination with land surface information like elevation, slopes, location, etc. can support urban growth modelling substantially (Cheng \& Masser, 2003; Hill \& Lindner, 2010). The anticipation of urban dynamics serves as a valuable planning tool for sustainable development, due to its capability to base informed decisions on various scenarios.

For sustainable urban planning the variety of geo-spatial results need a standardized format to be integrated in an easy to handle geo-information-system (Wahl, Schnabel \& Klein, 2008). Thus, the results can be visualized and used for quantitative analysis for specific problems. The higher-ranking goal is supporting the process of urban planning with the provision of objective, quantitative and area-wide data for more informed decisions.

\section{Conclusion and outlook}

The study has demonstrated that earth observation data, methods and products can significantly support identification, localization and evaluation of vulnerability and risks in cities. The main findings and results address the three questions we defined earlier in the introduction.

In general, remote sensing enables an independent, up-to-date, geometrically and thematically highly resolved analysis of the physical urban environment as well as the assessment of indirect parameters like e.g. the population distribution. High resolution sensors are especially valuable due to the small-scale heterogeneous structure typical for urban environments. Furthermore, interdisciplinary analysis allows value-adding such as the assessment of building stability with methods of civil engineering.

The conceptual framework shows the multi-disciplinarity and multi-dimensionality of vulnerability and risk. Remote sensing can only contribute bits and pieces to the holistic concept being one essential scientific discipline especially strong in the derivation of physical vulnerability indicators. Indirect correlation methods in interdisciplinary approaches allow contributions to demographic, social or economic vulnerability parameters. Thus, we need to overcome the problem of marginal or isolated questions failing to integrate them on higher-ranking goals without collaborating with other research disciplines.

Furthermore the spatial exposure on various hazards, in our case, the assessment of potential inundation areas of a tsunami or landslide prone areas can be assessed using earth observation data. .

These vulnerability studies and the geo-spatial products are of essential importance in an actual disaster case. The rapid mapping products were delivered within hours and days after the earthquake in Padang in 2009 with a never before seen thematic and geometrical resolution, due to their availability beforehand. Thus, rapid crisis intervention and knowledge generation needs this preparedness for the highly detailed statements.

Earth observation data and methods deliver objective and quantitative geo-spatial results or products with accuracies mostly above $80 \%$ and sometimes even higher. Thus, remote sensing has the capability to provide an objective basis for informed decisions needed for sustainable urban planning or the development of risk mitigation strategies. But these earth observation products are not yet established in the decision-making process, acceptance needs to be found by users, politicians and a legal foundation needs to be found for juristic acceptance. 
Within a different study of Mery Corps (2010) after the earthquake in Padang in 2009, perhaps the most important finding of the survey is that six months after the earthquake, many people continue living in unsafe housing. Rebuilding rates are extremely low compared to the number of damaged houses. This underlines, that transforming knowledge into action is a major challenge for success to rebuild resilient city. Thus, future work needs to include the last step of bringing information gained from science into action. The scientific results are valueless if they do not transform into practical value.

\section{References}

Birkmann, J. (2006): Measuring vulnerability to promote disaster-resilient societies: Conceptual frameworks and definitions, in: Measuring Vulnerability to Natural hazards - Towards Disaster Resilient Societies, edited by: Birkmann, J., New York, United Nations University, 9-54, 2006.

Birkmann, J., Dech, S., Goseberg, N., Lämmel, G., Moder, F., Nagel, K., Oczipka, M., Schlurmann, T., Setiadi, N., Siegert, F., Strunz, G. and Taubenböck, H.: Numerical Last-Mile Tsunami Early Warning and Evacuation Information System, in: International Conference on TsunamiWarning (ICTW), Bali, Indonesia, 12 pp., 12-14 November 2008a.

Blaikie, P., Cannon, T., Davis, I. \& Wisner, B. (1994): At Risk: Natural Hazards, People's Vulnerability and Disasters. London: Routeledge. S. 320.

Bogardi, J. and Birkmann, J.: Vulnerability Assessment: The First Step Towards Sustainable Risk Reduction, In: Disaster and Society - From Hazard Assessment to Risk Reduction, edited by: Malzahn, D. and Plapp, T., Logos Verlag Berlin, Berlin, 75-82, 2004.

Bohle H.-G.: Vulnerability and Criticality: Perspectves from Social Geography, IHDP Update 2/2001, Newsletter of the International Human Dimensions Programme on Global Environmental Change, 1-7, 2001.

Bollin, C., Hidajat, R. (2006): Community-based risk index: Pilot implementation in Indonesia. In: Birkmann, J. (2006): Measuring Vulnerability to Natural hazards - Towards Disaster Resilient Societies. New York, United Nations University. S. 524.

Borrero, J. C.; Sieh, K.; Chlieh, M. \& Synolakis, C. E. (2006): Tsunami inundation modeling for western Sumatra. Proceedings of the National Academy of Science of the United States of America, 2006, 103, 19673-19677. PNAS online publication, available at http://www.pnas.org

Brakenridge, G. R., Anderson, E., Nghiem, S. V., Caquard, S., Shabaneh, T. B. (2003): Flood warnings, flood disaster assessments, and flood hazard reduction: The roles of orbital remote sensing. Proceedings of the 30th International Symposium on Remote Sensing of Environment.

Briuglio, L. (2003): Methodological and Practical Considerations for Constructing Socio-Economic Indicators to Evaluate Disaster Risk. Institute of Environmental Studies, University of Columbia, Manizalez, Colombia. Programme on Information and Indicators for Risk Management. IADBECLAC- IDEA.

Cannon, T., Twigg, J., and Rowell, J. (2003): Social Vulnerability: Sustainable Livelihoods and Disasters, Report to DFID Conflict and Humanitarian Assistance Department (CHAD) and Sustainable Livelihoods Support Office, http://www.proventionconsortium.org/themes/default/pdfs/CRA/DFIDSocialv ulnerability.pdf. 
Chen, P., Liew, S. C., and Kwoh, L. K. (2005). Tsunami damage assessment using high resolution satellite imagery: a case study of Aceh, Indonesia. Proceedings, International Geoscience and Remote Sensing Symposium (IGARSS), Seoul, South Korea.

Cheng, J. \& Masser, I. (2003): Urban growth pattern modelling: a case study of Wuhan city, PR China. In: Landscape and Urban Planning, 62, 2003, 199 - 217.

Correira, F., Santos, M. \& Rodrigues, R. (1987): Engineering Risk in Regional Drought Studies. In: L. Duckstein and E.J. Plate, (eds.), Engineering Reliability and Risk in Water Resources, Dordrecht/Boston: Martinus Nijhoff, S. 61-86.

Correll, R., Cramer, W., and Schellnhuber, H.-J.: Potsdam sustainability days, Symposium on "Methods and Models of Vulnerability Research, Analysis and Assessment", 2001.

Davidson, R. (1997): An Urban Earthquake Disaster Risk Index, The John A. Blume Earthquake Engineering Center, Department of Civil Engineering, Stanford University, Stanford, Report No. 121, 1997.

Dech, S. \& R. Messner (2005): Berge aus dem All. Frederking \& Thaler, München.

Eguchi, R.T., Huyck, C.K., Houshmand, B., Shinozuka, M., Yamazaki, F., Matsuoka, M. and Ulgen, S. (2000): The Marmara Turkey Earthquake: Using Advanced Technology to Conduct Earthquake Reconnaissance. Research Progress and Accomplishments, 19992000, MCEER-00-SP01, Multidisciplinary Center for Earthquake Engineering Research, University at Buffalo.

Esch. T, Thiel M., Schenk A., Roth A., Mehl H., Dech S. (2010): Delineation of Urban Footprints from TerraSAR-X Data by Analyzing Speckle Characteristics and Intensity Information, In: IEEE - Transactions on Geoscience and Remote Sensing. vol. 48, no. 2, pp. 905916, Feb. 2010.

Füssel, H. M. (2005): Vulnerability in climate change research: A comprehensive conceptual framework. University of California, International and Area Studies - Breslauer Symposium No. 6.

Gonzalez, R. R. \& Medina, J. S. (2004): Theories, Models and Urban Realities. From New York to Kathmandu. In: Dela 21, pp. 64-81.

Goseberg, N. \& Schlurmann, T. (2009): Enhanced hazard mapping on a medium-resolved numerical grid for the city of Padang, West Sumatra. In: Journal of Ship Technology 5, July, Nr. 2, S. 13-2,1.

Gusella, L., Huyck, C. \& Adams, B.J. (2008): Counting the number of collapsed buildings using an object-oriented analysis: Case study of the 2003 Bam earthquake, Remote Sensing for Resilient Multi-hazard Disaster Response, Volume II, MCEER: Buffalo.

Hill, A.; Lindner, C. (2010): Simulating informal urban growth in Dar es Salaam, Tanzania - A CA-based land-use simulation model supporting strategic urban planning. In: Koch, A.; Mandl, P. (Eds.): Modeling and simulating urban processes, Lit Verlag, Münster (forthcoming)

Huyck, C. H., Adams, B.J., Cho, S., Chung, H.-C., Eguchi, R. T. (2005): Towards Rapid Citywide Damage Mapping Using Neighborhood Edge Dissimilarities in Very HighResolution Optical Satellite Imagery - Application to the 2003 Bam, Iran. In: Earthquake Spectra, December 2005, Vol. 21, Issue S1, pp. S255-S266

IPCC (2001): Impacts, Adaption, and Vulnerability, Published for the Intergovernmental Panel on Climate Change, University Press, Cambridge, ISBN 0-521-80768-9, 2001. 
Lämmel, G., Grether, D. \& Nagel, K. (2010): The representation and implementation of timedependent inundation in large-scale microscopic evacuation simulations. In: Transportation Research Part C: Emerging Technologies. vol. 18, pp. 84-98.

Lauterjung, J. \& Rudloff, A. (2005): GITEWS - The German Indonesian Tsunami Early Warning System, EOS T. Am. Geophys. Un., 86(52), Fall Meet. Suppl., 2005.

Leone, F., Denain, J.-C., Vinet, F., Bachri, S., (2007): Analyse spatiale des dommages au bâti de Banda Aceh (Sumatra, Indonésie): contribution à la connaissance du phénomène et à l'élaboration de scénarios de risque tsunami. In: Lavigne, F., Paris, R., in press. Le tsunami du 26 décembre 2004 en Indonésie - Rapport scientifique du programme TSUNARISQUE (2005-2006). Délégation Interministérielle pour l'aide PostTsunami (DIPT), Ambassade de France en Indonésie, Centre National de la Recherche Scientifique: $356 \mathrm{p}$.

Mas, J.-F. (1999): Monitoring land-cover changes: A comparison of change detection techniques. International Journal of Remote Sensing, 20(1), 139-152.

Mather, P. M. (2004): Computer Processing of Remotely-Sensed Images: An Introduction. Third Edition John Wiley. p. 292.

McCloskey, J., Lange, D., Tilmann, F., Nalbant, S., Bell, A., D. Hillman Natawidjaja \& Rietbrock, A. (2010): The September 2009 Padang Earthquake. Nature Geoscience, Correspondence.

Mercy Corps (2010): Padang houses by house - A Padang housing and vulnerability assessment,http:/ / prattinfographicsworkshop.files.wordpress.com/2010/08/2010july-29-final-english-padang-housing-and-vulnerability-assessment-hires.pdf

Miura., H. and Midorikawa, S. (2006): Updating GIS building inventory data using highresolution satellite images for earthquake damage assessment, Earthquake Spectra, 22(4): 151-168.

Münich, J., Taubenböck, H., Stempniewski, L., Dech, S., Roth, A. (2006): Remote sensing and engineering: An interdisciplinary approach to assess vulnerability in urban areas, First European Conference on Earthquake Engineering and Seismology. Geneva, Switzerland. p. 10 on CD-ROM.

Pesaresi, M. , Gerhardinger, A. \& Haag, F.(2007): Rapid damage assessment of built-up structures using VHR satellite data in tsunami-affected areas, In: International Journal of Remote Sensing, 28: 13, 3013 - 3036

Post, J., Wegscheider, S., Mück, M., Zosseder, K., Kiefl, R., Steinmetz, T., \& Strunz, G. (2009): Assessment of human immediate response capability related to tsunami threats in Indonesia at a sub-national scale, Nat. Hazards Earth Syst. Sci., 9, 1075-1086, doi:10.5194/nhess9-1075-2009, 2009.

Rashed, T. \& Weeks, J. (2003): Assessing vulnerability to earthquake hazards through spatial multicriteria analysis of urban areas, International Journal of Geographical Information Science, 17(6), 547-576.

Rastogi, B. K. and Jaiswal, R. K. (2006): A Catalogue of Tsunamis in the Indian Ocean, Science of Tsunami Hazards, 25(3), 128-143, 2006.

Roemer, H.; Kaiser, G.; Sterr, H. \& Ludwig, R. (2010): Using remote sensing to assess tsunamiinduced impacts on coastal forest ecosystems at the Andaman Sea coast of Thailand. Nat. Hazards Earth Syst. Sci., vol. 10, 729-745.

Saito, K., Spence, R. \& Foley, T. (2005): Visual damage assessment using high-resolution satellite images following the 2003 Bam Iran earthquake, Earthquake Spectra, Special Issue 1, Vol 21, 2005, pp. 309-318. 
Saito, K \& Spence, R. (2003): Using high-resolution satellite images for post earthquake building damage assessment: A study following the 26.1.01 Gujurat earthquake, Earthquake Spectra.

Sarabandi, P., Kiremidjian, A., Eguchi, R. T. and Adams, B.J., (2008) Building inventory compilation for disaster management: Application of remote sensing and statistical modeling, Technical Report Series MCEER-08-0025, MCEER: Buffalo.

Setiadi, N., Taubenböck, H., Raupp, S. \& Birkmann, J. (2010): Integrating socio-economic data in spatial analysis: An exposure analysis method for planning urban risk mitigation. $15^{\text {th }}$ International Conference on Urban Planning and Regional Development in the Information Society (REALCORP), Vienna, Austria. GeoMultimedia 2010. pp. 367374.

Schneiderbauer, S. (2007): Risk and Vulnerability to Natural Disasters - from Broad View to Focused Perspective, PhD-Thesis, Freie Universit"at Berlin, pp. 121, available at: http://www.diss.fu-berlin.de/2007/498/indexe.html .

Taubenböck, H., Esch, T., Felbier, A., Roth, A. \& Dech, S. (2011): Pattern-based accuracy assessment of an urban footprint classification using TerraSAR-X data. In: IEEE Geoscience and Remote Sensing Letters. Vol. 8; No. 2; pp. 5; March 2011.

Taubenböck H. \& Dech, S. (2010): Remote Sensing and Urban Planning: A Common Future? In: V1 Magazine - Promoting Spatial Design for a Sustainable Tomorrow. http:/ / www.vector1media.com/articles/features/13931-remote-sensing-andurban-planning-a-common-future-

Taubenböck, H., Esch, T., Wurm, M., Roth, A. \& Dech, S. (2010): Object-based feature extraction using high spatial resolution satellite data of urban areas. In: Journal of Spatial Science, vol. 55, no. 1., pp. 117-133.

Taubenböck, H., Goseberg, N., Setiadi, N., Lämmel, G., Moder, F., Oczipka, M., Klüpfel, H., Wahl, R., Schlurmann, T., Strunz, G., Birkmann, J., Nagel, K., Siegert, F., Lehmann, F., Dech, S., Gress, A., Klein R. (2009a): Last-Mile preparation for a potential disaster Interdisciplinary approach towards tsunami early warning and an evacuation information system for the coastal city of Padang, Indonesia. In: Nat. Hazards Earth Syst. Sci.. Vol. 9, pp. 1509-1528. http://www.nat-hazards-earth-syst-sci.net/9/1509/2009/nhess-91509-2009.html

Taubenböck, H., Wurm, M., N. Setiadi, N. Gebert, A. Roth, G. Strunz, J. Birkmann \& S. Dech (2009b): Integrating Remote Sensing and Social Science - The correlation of urban morphology with socioeconomic parameters. In: Urban Remote Sensing Joint Event, Shanghai, China. pp. 7, CD-ROM.

Taubenböck, H., Post, J., Roth, A., Zosseder, K., Strunz, G. \& Dech, S. (2008): A conceptual vulnerability and risk framework as outline to identify capabilities of remote sensing. In: Nat. Hazards Earth Syst. Sci.. Vol. 8, no. 3, pp. 409-420. http://www.nat-hazardsearth-syst-sci.net/8/409/2008/ nhess-8-409-2008.html

Timmermann, P. (1981): Vulnerability, Resilience and the Collapse of Society, No. 1 in Environmental Monograph, Toronto: Institute for Environmental Studies, University of Toronto.

Turner, B. L., Kasperson, R. E., Matson, P. A., McCarthy, J. J., Corell, R. W., Christensen, L., Eckley, N., Kasperson, J. X., Luers, A., Martello, M. L., Polsky, C., Pulsipher, A., and Schiller, A. (2003): A framework for vulnerability analysis in sustainability science, P. Natl. Acad. Sci. USA, 100(14), 8074-8079, 2003. 
Turker, M. \& Cetinkaya, B. (2005): Automatic detection of earthquake-damaged buildings using DEMs created from pre- and post-earthquake stereo aerial photographs, In: International Journal of Remote Sensing, 26, pp. 823-832.

United Nations (1991): Mitigating Natural Disasters: Phenomena, Effects, and Options: a Manual for Policy Makers and Planners, New York: UNDRO (United Nations Disaster Relief Organization), 1991.

United Nations Development Programme (UNDP) (2004): Reducing Disaster Risk - A challenge for development - A Global Report, ISBN 92-1-126160-0, New York, USA, 2004.

United Nations/ISDR (International Strategy for Disaster Reduction) (2004): Living with Risk: A Global Review of Disaster Reduction Initiatives, United Nations International Strategy for Disaster Reduction, UN Publications, Geneva, Switzerland, 2004.

United Nations University Institute for Environment and Human Security (UNU-EHS) (2008): Household Survey on Socio-Economic Vulnerability to Tsunamis in Padang City.

Voigt, S., Kemper, T., Riedlinger, T., Kiefl , R., Scholte, K., \& Mehl, H. (2007): Satellite image analysis for disaster and crisis-management support, IEEE Transactions on Geoscience and Remote Sensing, 45(6), 1520-1528.

Wahl, R., Schnabel, R. \& Klein, R. (2008): From Detailed Digital Surface Models to City Models Using Constrained Simplification. Photogrammetrie, Fernerkundung, Geoinformation (2008):3(207-215)

Zschau, J., Isikara, M., Ergünay, O, Yalcin, M.N., Erdik, M. (2002): Towards an earthquake early warning system for the megacity Istanbul. Early Warning Systems for Natural Disaster Reduction, edited by J.Zschau and A.Küppers, pp.433-440, Springer. 


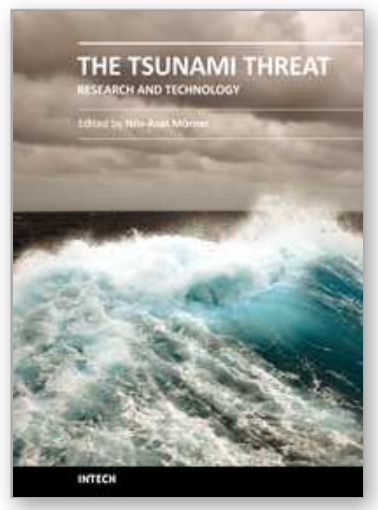

\author{
The Tsunami Threat - Research and Technology \\ Edited by Nils-Axel MÃ $\Uparrow$ rner
}

ISBN 978-953-307-552-5

Hard cover, 714 pages

Publisher InTech

Published online 29, January, 2011

Published in print edition January, 2011

Submarine earthquakes, submarine slides and impacts may set large water volumes in motion characterized by very long wavelengths and a very high speed of lateral displacement, when reaching shallower water the wave breaks in over land - often with disastrous effects. This natural phenomenon is known as a tsunami event. By December 26, 2004, an event in the Indian Ocean, this word suddenly became known to the public. The effects were indeed disastrous and 227,898 people were killed. Tsunami events are a natural part of the Earth's geophysical system. There have been numerous events in the past and they will continue to be a threat to humanity; even more so today, when the coastal zone is occupied by so much more human activity and many more people. Therefore, tsunamis pose a very serious threat to humanity. The only way for us to face this threat is by increased knowledge so that we can meet future events by efficient warning systems and aid organizations. This book offers extensive and new information on tsunamis; their origin, history, effects, monitoring, hazards assessment and proposed handling with respect to precaution. Only through knowledge do we know how to behave in a wise manner. This book should be a well of tsunami knowledge for a long time, we hope.

\title{
How to reference
}

In order to correctly reference this scholarly work, feel free to copy and paste the following:

Hannes Taubenböck (2011). The Vulnerability of a City - Diagnosis from a Bird's Eye View, The Tsunami Threat - Research and Technology, Nils-Axel MÃ rner (Ed.), ISBN: 978-953-307-552-5, InTech, Available from: http://www.intechopen.com/books/the-tsunami-threat-research-and-technology/the-vulnerability-of-a-citydiagnosis-from-a-bird-s-eye-view

\section{INTECH}

open science | open minds

\section{InTech Europe}

University Campus STeP Ri

Slavka Krautzeka 83/A

51000 Rijeka, Croatia

Phone: +385 (51) 770447

Fax: +385 (51) 686166

www.intechopen.com

\section{InTech China}

Unit 405, Office Block, Hotel Equatorial Shanghai

No.65, Yan An Road (West), Shanghai, 200040, China

中国上海市延安西路65号上海国际贵都大饭店办公楼 405 单元

Phone: +86-21-62489820

Fax: +86-21-62489821 
(C) 2011 The Author(s). Licensee IntechOpen. This chapter is distributed under the terms of the Creative Commons Attribution-NonCommercialShareAlike-3.0 License, which permits use, distribution and reproduction for non-commercial purposes, provided the original is properly cited and derivative works building on this content are distributed under the same license. 